\title{
ОЦЕНКА КАРДИОВАСКУЛЯРНОЙ ПАТОЛОГИИ У БОЛЬНЫХ В-КРУПНОКЛЕТОЧНОЙ ЛИМФОМОЙ В ДИНАМИКЕ ХИМИОТЕРАПИИ
}

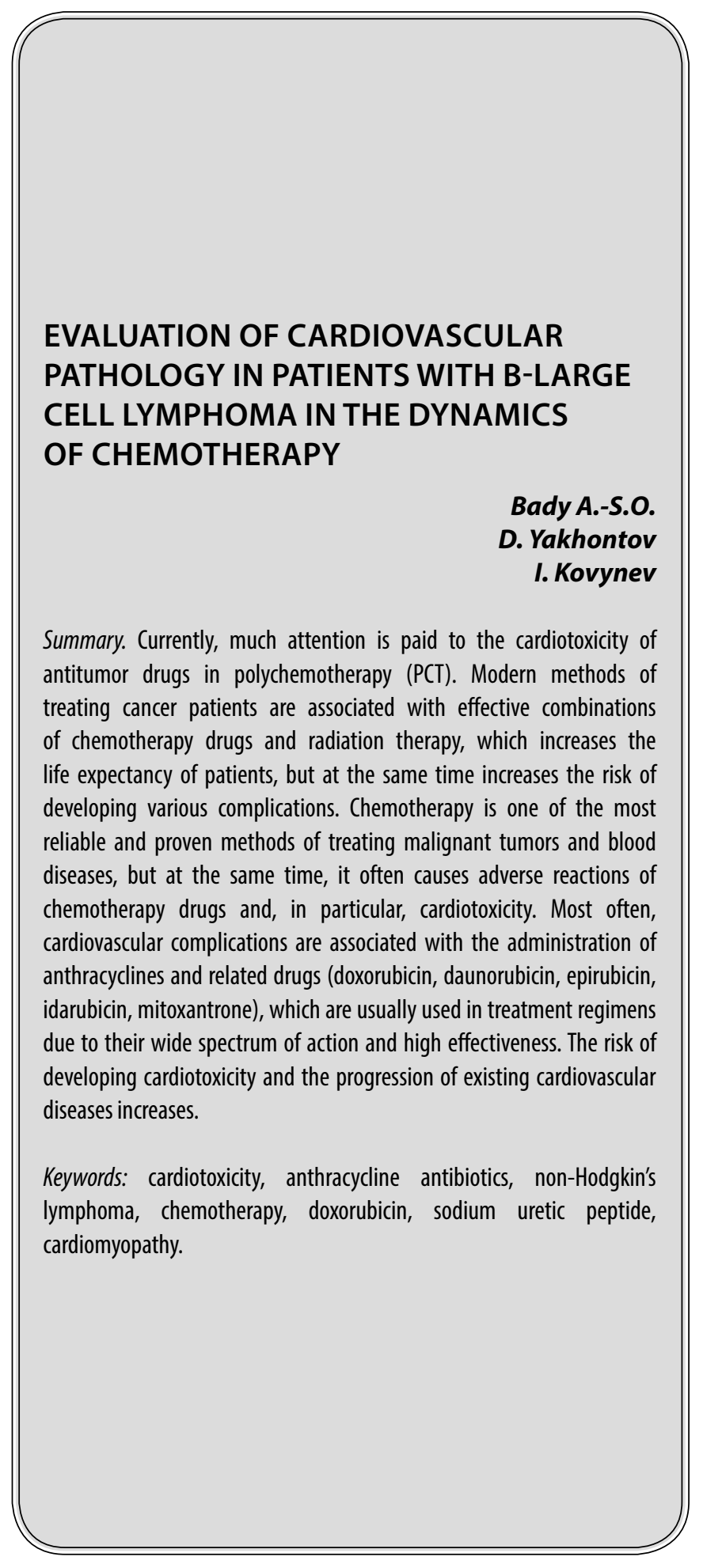

\author{
Бады Ай-Суу Онер-ооловна \\ Аспирант, ФГБОУ ВО «Новосибирский \\ Государственный Медицинский Университет» \\ Минздрава России, г. Новосибирск \\ arven1951@mail.ru \\ Яхонтов Давыд Александрович \\ Д.м.н., профессор, ФГБОУ ВО «Новосибирский \\ Государственный Медицинский Университет» \\ Минздрава России, г. Новосибирск \\ mich99@mail.ru \\ Ковынев Игорь Борисович \\ Д.м.н., профессор, ФГБОУ ВО «Новосибирский \\ Государственный Медицинский Университет» \\ Минздрава России, г. Новосибирск \\ kovin_gem@mail.ru
}

Аннотация. В настоящее время большое внимание уделяется кардиотоксичности противоопухолевых препаратов при полихимиотерапии (ПХТ). Современные методы лечения онкологических больных связаны с эффективными комбинациями химиотерапевтических препаратов и лучевой терапии, что увеличивает продолжительность жизни больных, но при этом увеличивается риск развития различных осложнений. Химиотерапия является одним из самых надёжных и проверенных методов лечения злокачественных опухолей и заболеваний крови, но вместе с тем на ее фоне часто возникают побочные реакции химиопрепаратов и, в частности, кардиотоксичность. Наиболее часто сердечно-сосудистые осложнения связаны с назначением антрациклинов и родственных им препаратов (доксорубицин, даунорубицин, эпирубицин, идарубицин, митоксантрон), которые обычно используются в схемах лечения из-за широкого спектра действия и высокой эффективности. Риск развития кардиотоксичности и прогрессирования уже имеющихся сердечно-сосудистых заболеваний увеличивается в зависимости от дозы препарата, включенного в схему лечения, возраста пациента, наличия кардиоваскулярных факторов риска и сердечно-сосудистых заболеваний в анамнезе. С целью оценки кардиоваскулярной патологии у больных злокачественными неходжкинскими лимфомами было обследовано 79 пациентов с установленным диагнозом В-крупноклеточная лимфома. Характер кардиоваскулярной патологии оценивался исходно до проведения ПХТ и через 1 год после 4-6 курсов ПХТ во время клинико-гематологической ремиссии. Изменения со стороны сердца после ПХТ привели к увеличению размеров полостей сердца по данным эхокардиографии (ЭхоКГ) и увеличению значений мозгового натрий уретического пептида (NTproBNP), как основного биомаркера миокардиальной дисфункции.

Ключевые слова: кардиотоксичность, антрациклиновые антибиотики, неходжкинские лимфомы, химиотерапия, доксорубицин, натрий уретический пептид, кардиомиопатия. 


\section{Ввемение}

5 локачественные лимфомы составляют примерно $2 \%$ от всех злокачественных новообразований кроветворной и лимфоидной ткани. При этом данные лимфомы чаще встречаются в детском возрасте и у молодых людей [1]. Злокачественные неходжкинские лимфомы почти в 2 раза превышают показатель заболеваемости в сравнении с лимфомой Ходжкина [2]. С развитием методов ранней диагностики и появлением новых противоопухолевых препаратов для лечения онкологических больных увеличивается продолжительность и качество жизни. Однако, при этом возникает кардиотоксическое поражение противоопухолевых препаратов и, как следствие, рост сердечно-сосудистых заболеваний, инвалидности и смертности у данной категории пациентов [7]. Неходжкинские лимфомы (НХЛ) являются гетерогенной группой злокачественных лимфопролиферативных заболеваний крови, характеризирующейся неопластической пролиферацией незрелых лимфоидных клеток вне костного мозга [4, 5]. Основные принципы лечения НХЛ опирается на ряд факторов: иммунофенотип (В-клеточный или Т-клеточный), морфологический вариант и его отношение к группам, отличающимся по признаку агрессивности течения (индолентные и агрессивные НХЛ), степень распространения опухоли (стадия), наличие или отсутствие интоксикации (А и В симптомы), индивидуальный прогноз, определяемый как степень риска по так называемому Интернациональному прогностическому индексу (IPI). Существует 25 вариантов химиотерапии для индолентных НХЛ и 42 варианта для НХЛ высокой степени злокачественности [6]. Для общих алгоритмов лечения НХЛ в каждом случае определяющим для выбора принципов лечения является их разделение согласно классификации ВОЗ 2017 г. (пересмотр 4-го издания) [9, 10]. Полихимиотерапия (ПХТ) является одним из самых надёжных и проверенных методов лечения злокачественных опухолей и заболеваний крови. Однако, клинический эффект химиопрепаратов не всегда сопоставим с их профилем безопасности, поэтому возникает необходимость изучения проблем, связанных с побочными реакциями химиопрепаратов и, в частности, их кардиотоксичностью [8]. По данным Американского общества клинической онкологии и Национального института изучения и лечения рака США, вторым по значимости критерием оценки результатов противоопухолевого лечения после выживаемости является качество жизни пациентов, на которое существенное влияние оказывают отдаленные токсические последствия химиотерапии [15]. Применение антрациклиновых антибиотиков ограничено кумулятивным и дозозависимым кардиотоксическим действием [3]. Антрациклиновая кардиотоксичность делится на острую (менее $1 \%$ случаев, зачастую обратимая, но тяжело протекающая); остро начавшаяся хроническая прогрессирующая (1.6-2.1\% случаев в течение 1 года); поздно начавшаяся прогрессирующая (1.6-2.5\% случаев через год после окончания лечения); отдаленная (через 10-20 лет после завершения химиотерапии) [16]. К факторам риска развития кардиотоксического действия химиотерапевтического лечения относят режим химиотерапии, возраст, ожирение, гиподинамию, наличие сердечно-сосудистых заболеваний. Нарушение систолической функции левого желудочка (ЛЖ), индуцированное доксорубицином, связано с ранними изменениями симпатико-парасимпатического баланса с преобладанием симпатического тонуса [11]. Все чаще в различных рекомендациях по диагностике и лечению сердечной недостаточности говорится о токсических и лучевых воздействиях на миокард как непосредственного этиологического фактора [12]. Изучение биомаркеров, свидетельствующих о специфическом повреждении тканей и органов, таких как тропонин I, миоглобин, мозговой натрий-уретический пептид (NTproBNP), привели к их широкому использованию в ранней диагностике заболеваний сердечно-сосудистой системы. Высокочувствительные биомаркеры могут помочь в определении риска кардиотоксичности и оценки развития сердечно-сосудистой патологии [13].

Широко представлены работы по изучению кардиотоксического действия антрациклинов у пациентов, получавших высокие суммарные дозы этих препаратов, превышающие пороговую величину, однако малоизученными остаются оценка изменений сердечно-сосудистой системы у больных, которые получали небольшие суммарные дозы данных препаратов в динамике химиотерапии, а также вопросы взаимосвязи течения основного заболевания с морфометрическими показателями миокарда и показателями центральной гемодинамики в процессе ПХТ [14].

\section{Цель исслеАования}

Оценить состояние сердечно-сосудистой системы и характер кардиоваскулярной патологии у больных В-крупноклеточной лимфомой высокой степени агрессивности в дебюте заболевания и через 1 год после окончания химиотерапии на стадии клинико-гематологической ремиссии.

\section{Материалы и метолы}

Проведено проспективное когортное исследование 79 пациентов с установленным диагнозом с, в том числе 38 мужчин и 41 женщин. Обследование больных проводилось исходно - до начала химиотерапии при установлении диагноза В-крупноклеточной лимфомой и в фазе стойкой клинико-гематологической ремиссии (после 4-6 курсов ПХТ). Все пациенты наблюдались врачом-гематологом. Всем пациентам выполнено стандартное об- 
Таблица 1. Факторы кардиоваскулярного риска у обследованных больных

\begin{tabular}{|l|l|l|l|}
\hline Показатель & Исходно $(\mathbf{n = 7 9 )}$ & Через год после ПХТ $(\mathbf{n = 7 9 )}$ & $\mathbf{P}$ \\
\hline АГ & $9(11.3 \%)$ & $11(13.9 \%)$ & 0.05 \\
\hline Офисное САД, мм Рт.ст. & $136.5 \pm 0.4$ & $147.1 \pm 0.5$ & 0.04 \\
\hline Офисное ДАД, мм Рт.Ст. & $88.7 \pm 0.5$ & $98.6 \pm 0.6$ & 0.05 \\
\hline АГ 1 степени & $6(7.5 \%)$ & $8(10.1 \%)$ & 0.04 \\
\hline АГ 2 степени & $2(2.5 \%)$ & $2(2.5 \%)$ & 0.08 \\
\hline АГ З степени & $1(1.2 \%)$ & $1(1.2 \%)$ & 0.08 \\
\hline Курение & $9(11.3 \%)$ & $8(10.1 \%)$ & 0.06 \\
\hline
\end{tabular}

следование перед началом ПХТ. В терапии агрессивных НХЛ были использованы стандартные протоколы I линии и высокодозные протоколы II линии (ритуксимаб, циклофосфан, доксорубицин, винкристин, преднизолон). В комплекс стандартного обследования входили первичный осмотр больного, электрокардиография (ЭКГ), ЭхоКГ (эхокардиография), ХМ ЭКГ (холтеровское мониторирование ЭКГ), УЗИ (ультразвуковое исследование) сонных артерий, определение уровня NT-proBNP.

Критерии включения в исследование: возраст от 18 до 60 лет, документированный диагноз неходжкинской лимфомы, наблюдение больного врачом-гематологом ГБУЗ НСО Городская клиническая больница № 2, подписание участником добровольного информированного согласия на участие в исследовании.

Критерии исключения из исследования: невозможность или нежелание дать добровольное информированное согласие на участие в исследовании, больные с декомпенсированным сахарным диабетом, ВИЧ-инфекцией, декомпенсацией любого соматического заболевания, наличием любого инфекционного или гнойно-воспалительного процесса.

Протокол исследования бы одобрен Комитетом по этике ФГБОУ ВО НГМУ Минздрава России.

Статистическая обработка полученных материалов. Статистическая обработка полученных результатов проводилась с помощью программы Statistica 6.1 и Statistica 10. Распределение считали нормальным при значении данных показателей от -2 до 2. Значения непрерывных величин были представлены в виде $\mathrm{M} \pm \sigma$, где М выборочное среднее арифметическое и $\sigma-$ стандартная ошибка среднего. Значение качественных признаков представлены в виде наблюдаемых частот процентов. В случаях нормального распределения, а также равенства выборочных дисперсий, для сравнения выборок использовали t-критерий Стьюдента. Уровень статистической значимости при проверке нулевой гипотезы принимали соответствующим $\mathrm{p}<0.05$. Во всех случаях использовали двухсторонние варианты критериев. При сравнении нескольких групп между собой использовали поправку Бонферрони на множественность сравнений. Обработку данных проводили с помощью компьютерных программ и Excel 2007.

\section{Результаты}

При анализе частоты кардиоваскулярных факторов риска выявлено, что курение встречалось у 9 (11.3\%) пациентов в группе обследуемых до начала ПХТ, а через 1 год после 4-6 курсов ПХТ было у 8 (10.1\%) пациентов. Артериальная гипертония (АГ) имела место у 9 (11.3\%) пациентов перед ПХТ, а через 1 год после 4-6 курсов ПХТ у $11(13.9 \%)$ пациентов (табл. 1).

При изучении кардиоваскулярного анамнеза наличие стенокардии напряжения было выявлено у 4 (\%) больных перед ПХТ, а через 1 год после 4-6 курсов ПХТ у 6 (7.5\%) больных. В анамнезе перенесенный инфаркт миокарда был зафиксирован 1 (1.2\%) больного до ПХТ. В динамике наблюдения через 1 год после 4-6 курсов ПХТ не было диагностировано случаев ОКС. При изучении нарушения ритма сердца, а именно частоты фибрилляции предсердий, выявлена у 1 (1.2\%) больных до ПХТ, а через 1 год после 4-6 курсов ПХТ у 2 (2.5\%) больных, при этом до ПХТ у больных преобладала пароксизмальная форма фибрилляции предсердий, то в динамике через 1 год после 4-6 курсов ПХТ отмечался переход пароксизмальной формы в длительно-персистирующую форму фибрилляции предсердий. При изучении цереброваскулярной патологии мозговый инсульт в анамнезе был у 1 (1.2\%) больных до ПХТ, а через 1 год после 4-6 курсов ПХТ не было диагностировано случаев ОНМК, но была ТИА у 1 (1.2\%) больного. Сахарный диабет 2 типа в стадии медикаментозной компенсации был у 2 (2.5\%) больных до ПХТ, а через 1 год после 4-6 курсов ПХТ новых случаев СД не было выявлено (табл. 2).

По данным ХМ ЭКГ суправентрикулярные экстрасистолы высокой градации зарегистрированы у 3 (3.7\%) больных до ПХТ, а через 1 год у 4 (5.0\%); частота желудочковых экстрасистол составила $1.2 \%$ и $2.5 \%$ соответственно. 
Таблица 2. Заболевания сердечно-сосудистой системы у обследованных больных

\begin{tabular}{|c|c|c|c|}
\hline Заболевание & Исходно (n=79) & $\begin{array}{l}\text { Через год после ПХТ } \\
(\mathrm{n}=79)\end{array}$ & $\mathbf{P}$ \\
\hline Стенокардия напряжения, n (\%) & $4(5.0 \%)$ & $6(7.5 \%)$ & 0.05 \\
\hline IФK & $2(2.5 \%)$ & $4(5.0 \%)$ & 0.06 \\
\hline$\| \Phi K$ & $1(1.2 \%)$ & $2(2.5 \%)$ & 0.04 \\
\hline III ФK & - & - & - \\
\hline $\begin{array}{l}\text { Экстрасистолия } \\
\text { наджелудочковая } \\
\text { желудочковая }\end{array}$ & $\begin{array}{l}3(3.7 \%) \\
2(2.5 \%) \\
1(1.1 \%) \\
\end{array}$ & $\begin{array}{l}4(5.0 \%) \\
2(2.5 \%) \\
2(2.5 \%) \\
\end{array}$ & $\begin{array}{l}0.04 \\
0.07 \\
0.04\end{array}$ \\
\hline $\begin{array}{l}\text { Фибрилляция предсердий } \\
\text { пароксимальная форма } \\
\text { персистирующая форма }\end{array}$ & $\begin{array}{l}1(1.2 \%) \\
1(1.2 \%) \\
- \\
\end{array}$ & $\begin{array}{l}2(2.5 \%) \\
1(1.2 \%) \\
1(1.2 \%) \\
\end{array}$ & $\begin{array}{l}0.05 \\
0.05 \\
-\quad \\
\end{array}$ \\
\hline Инфаркт миокарда в анамнезе & $1(1.2 \%)$ & - & - \\
\hline Инсульт в анамнезе & $1(1.2 \%)$ & - & - \\
\hline TИA & - & $1(1.2 \%)$ & - \\
\hline $\mathrm{XCH}$ & $11(13,9 \%)$ & $17(21.5 \%)$ & 0.05 \\
\hline $\mathrm{XCH} I \mathrm{NYHA}$ & $10(12.6 \%)$ & $12(15.1 \%)$ & 0.05 \\
\hline XCH II NYHA & $1(1.2 \%)$ & $5(6.3 \%)$ & 0.04 \\
\hline XCH III NYHA & - & - & - \\
\hline
\end{tabular}

Таблица 3. Показатели УзИ сердца

\begin{tabular}{|l|l|l|l|}
\hline Показатели & Исходно $(\mathbf{n = 7 9 )}$ & $\begin{array}{l}\text { Через год после ПХТ } \\
(\mathbf{n = 7 9 )}\end{array}$ & $\mathbf{P}$ \\
\hline ЛП, см & $2.5 \pm 0.5$ & $3.1 \pm 0.8$ & 0.04 \\
\hline КДР, см & $4.1 \pm 0.7$ & $5.9 \pm 1.1$ & 0.03 \\
\hline КСР, см & $3.4 \pm 0.8$ & $3.9 \pm 1.1$ & 0.08 \\
\hline ФВ,\% & $61.2 \pm 1.1$ & $55.1 \pm 1.1$ & 0.04 \\
\hline Зоны гипо-, акинеза & $1(1.2 \%)$ & $1(1.2 \%)$ & 0.09 \\
\hline $\begin{array}{l}\text { ИММЛЖ, г/м² } \\
\text { Жужчины }\end{array}$ & $78.0 \pm 1.3$ & $\begin{array}{l}101.0 \pm 2.5 \\
99.0 \pm 2.3\end{array}$ & 0.03 \\
\hline
\end{tabular}

По данным теста 6 минутной ходьбы ХСН II и III ФК значимо чаще диагностировалась через год после 4-6 курсов ПХТ у 17 (21.5\%) больных, тогда как до ПХТ было лишь у 11 (13.9\%) больных. Уровень NT-proBNP как раннего маркера миокардиальный дисфункции у больных

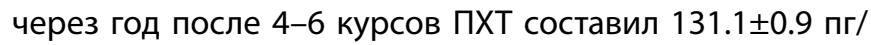

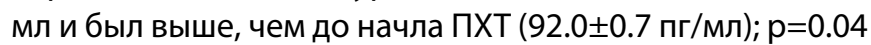
при норме до 125 пг/мл. При проведении УзИ сердца значения КДР, КСР и ИММЛЖ у больных через 1 год после 4-6 курсов ПХТ были выше, чем у больных до ПХТ. Также у больных через 1 год после 4-6 курсов ПХТ было снижение показателей фракции выброса несмотря на отсутствие сердечно-сосудистых событий, как перенесенный инфаркт миокарда у больных (табл. 3).

По данным УЗИ БЦА лишь у одного больного через 1 год после 4-6 курсов ПХТ во время клинико-гематологической ремиссии был обнаружен гемодинамически незначимый стеноз.
Анализ показателей липидного спектра выявил более высокие значения ОХС и его атерогенных фракций через 1 год после 4-6 курсов ПХТ во время клинико-гематологической ремиссии (табл. 4). Также у этих больных было увеличение показателей гликемии, мочевины, креатинина и уровень микроальбуминурии. Поражение почек подтверждается также снижением значений расчетной скорости клубочковой фильтрации, которые состав-

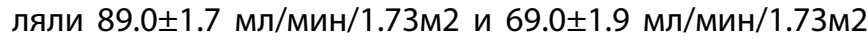
соответственно $(p<0,05)$. Более низкие показатели СРБ во время клинико-гематологической ремиссии вероятно связаны с сохраняющимся иммуносупрессивным эффектом ПХТ на фоне клинико-гематологической ремиссии (табл. 4).

\section{Зак^ючение}

Через 1 год после 4-6 курсов ПХТ были обнаружены изменения размеров полостей сердца и величины ИММ- 
Таблица 4. Лабораторные показатели обследованных больных

\begin{tabular}{|l|l|l|l|}
\hline Показатель & Исходно (n=79) & $\begin{array}{l}\text { Через год после ПХТ } \\
(\mathbf{n = 7 9 )}\end{array}$ & $\mathbf{P}$ \\
\hline ОХС (ммоль/л) & $3.6 \pm 0.2$ & $4.8 \pm 1.4$ & 0.05 \\
\hline ХС ЛПВП ммоль/л & $1.4 \pm 1.2$ & $1.0 \pm 1.2$ & 0.07 \\
\hline ХС ЛПНП, ммоль/л & $1.9 \pm 0.7$ & $2.9 \pm 0.8$ & 0.03 \\
\hline ТГ, ммоль/л & $1.4 \pm 0.1$ & $1.8 \pm 0.1$ & 0.06 \\
\hline Глюкоза, ммоль/л & $4.4 \pm 0.1$ & $5.2 \pm 0.1$ & 0.03 \\
\hline $\begin{array}{l}\text { МАУ, мг/сут } \\
\text { Женчинины }\end{array}$ & $23.1 \pm 1.2$ & 0.02 \\
\hline $\begin{array}{l}\text { Креатинин крови, ммоль/л } \\
\text { Мужчины }\end{array}$ & $21.3 \pm 1.2$ & 0.01 \\
\hline Женщины & $72.0 \pm 2.4$ & $45.1 \pm 0.2$ & 0.03 \\
\hline Расчетная СКФ, мл/мин/1.73м2 & $78.0 \pm 2.4$ & 0.01 \\
\hline Мочевина, ммоль/л & $89.0 \pm 1.7$ & $97.0 \pm 0.1$ & $101.0 \pm 0.1$ \\
\hline $\begin{array}{l}\text { Мочевая кислота, МОль/л } \\
\text { Женчины }\end{array}$ & $5.1 \pm 0.7$ & $69.0 \pm 1.9$ & 0.04 \\
\hline СРБ, мг/л & $311,6 \pm 7,2$ \\
\hline Фибриноген, г/л & $268,2 \pm 9,9$ & $8.4 \pm 0.9$ & 0.01 \\
\hline
\end{tabular}

ЛЖ по данным ЭхоКГ. Наряду с увеличением размеров сердца, также выявлено повышение значений NTproBNP. При этом доказано, что увеличение размеров сердца и прогрессирование ФК ХСН у больных через 1 год после 4-6 курсов ПХТ не сопровождался увеличением частоты ИБС, так и инфаркта миокарда. У больных через 1 год после 4-6 курсов ПХТ по сравнению до ПХТ с большей частотой встречалась АГ, также более высокие показатели САД и ДАД, что может отражать развитие некоронарогенной миокардиальной дисфункции у этих больных.

Выявлено, что б больных через 1 год после 4-6 курсов ПХТ были достоверно выше значения ХС ЛПНП и триглицеридов, что, вероятно, связано с нарушением липидного спектра после ПХТ, так и недостаточно частым назначением статинов.
У больных через 1 год после 4-6 курсов ПХТ выявлено повышение значений мочевины крови, креатинина крови, МАУ и более низкой СКФ, что, возможно, отражает прогрессирование не только кардиоваскулярного, но и кардиоренального континуума.

Таким образом, динамика В-крупноклеточной лимфомы на фоне курсов ПХТ может способствовать повышению показателей АД, морфометрическим сдвигам миокарда с формированием миокардиальной дисфункции, что подтверждается более высокими значениями NTproBNP и формированием нефропатии, что ведет к возникновению потребности в динамическом наблюдении и вмешательств с первых дней у больных В-крупноклеточной лимфомой.

\section{ЛИТЕРАТУРА}

1. Ковынев И.Б., Поспелова Т.И., Агеева Т.А., Лосева М.И., Воропаева Е.Н., Дьячкова Н.Ю. Частота и структура неходжкинских лимфом в Новосибирске, НСО и городах Сибирского Федерального округа. БЮЛЛЕТЕНЬ СО РАМН, № 4 (122), 2006. С. 175-181.

2. Дурнов Л. А., Голдобенко Г.В., Курмашов В.И. Детская онкология: Учебное издание.— Курск: КГМУ, Москва: Литера, 1997. — 400 с.

3. Гадаев И.Ю., Ершов В.И., Бочкарникова О.В., Соколова И.Я., Буданова Д.А., Котова В.С., Лишута А.С. Поражение сердца при лимфомах. Обзор литературы и описание случая клинического течения В-крупноклеточной лимфомы. Рациональная фармакотерапия в кардиологии, 2015; 11(6):610-617

4. Поддубная И.В. Неходжкинские лимфомы// Клиническая гематология: руководство для врачей. Глава 23. Под ред. А.М. Волковой. М: Медицина. С. $336-375$.

5. Воробьев А.И., Кременецкая А.М., Харазашвили Д.М., Воробьев И.А., Магомедова А.У. //В кн. Руководство по гематологии. Под редакцией Воробьева А.И. Издание третье переработанное и дополненное. Т2. С. 96-103.

6. Гендлин Г.Е., Сторожаков Г.И., Шуйкова К.В., Емелина Е.И., Клюшина Г.М., Миронков А.Б., Остроумова Е.И., Лепков С.В., Демина Е.А. Острые сердечно-сосудистые события во время применения противоопухолевых химиопрепаратов: клинические наблюдения. Клиническая онкология, 2011; 4(2):155-165 
7. Дорохина Е.И., Магомедова Ф.У., Двирнык В.Н., Гальцева И.В., Глинкина С.А., Куликов С.М., Обухова Т.Н., Кравченко С.К. Отдаленная миелотоксичность высокодозной химиотерапии по модифицированной программе NHL-BFM-90 у больных диффузной В-крупноклеточной лимфомой. ФГБУ «Гематологический научный центр» Минздрава России, Москва. Терапевтический архив 7, 2016 г.

8. Емелина Е. И., Гендлин Г.Е., Сторожаков Г.И., Лепков С.В., Демина Е.А. Динамика показателей эхокардиографии у больных лимфопролиферативными заболеваниями, получавших антрациклиновые препараты. Российский медицинский журнал № 1, 2007 г.

9. Крикунова 0.В., Васюк Ю.А., Висков Р.В., Крикунов П.В., Иванова С.В., Коник В.А. Сердечные тропонины в выявлении кардиотоксичности у пациентов подвергающихся химиотерапии. Российский кардиологический журнал. 2015;(12):119-125 https://doi.org/10.15829/1560-4071-2015-12-119-125

10. Лазнам С.С., Берштейн Л.Л., Гришкин Ю.Н. Значение оценки сердечно-сосудистого риска в прогнозировании ишемической болезни сердца. Вестник Российской Военно-Медицинской академии, 2011; 4(36):185-194

11. Мареев В.Ю., Агеев Ф.Т., Арутюнов Г.П. и др. Национальные рекомендации ОССН, РКО и РНМОТ по диагностике и лечению ХСН (четвертый пересмотр). Журнал Сердечная Недостаточность, 2013; 14, 7 (81)

12. Шуйкова К.В., Емелина Е.И., Гендлин Г.И., Сторожаков Г.И. Изменение функции левого желудочка сердца у больных слимфомами на фоне введения антрациклиновых антибиотиков. Российский кардиологический журнал 2016. 1 (129): 41-46

13. Hennessy B.T., Hanrahan E.0., Daly P.A. Non Hodgkin's lymphoma: an update // The Lancet Oncol.— 2004. — Vol.5. — P. $341,353$.

14. Raj S., Franco VI., Lipshultz SE., Anthracycline-incluced cardiotoxity; A RevieW of Pathophysiology, Diagnosis, and Treatment, Curr Treat Options Cardio Med (2014) 16:315.

15. Vergely C, Delemasure S, Cottin Y, Rochette L. Preventing the cardio-toxic effects of anthracyclines: from basic concepts to clinical data. Heart Metab 2007; 35: 1-7.

16. Zheng PP, Li J, Kros JM. Breakthroughs in modem cancer therapy and elusive cardiotoxicity: Critical research-practical gaps, challenges, and insights. Med Res Rev.2007 Sep 1. doi: 10.1002/med.21463. стр.1-3.

(с Бады Ай-Суу Онер-ооловна ( arven1951@mail.ru),

Яхонтов Давыд Александрович ( mich99@mail.ru ), Ковынев Игорь Борисович ( kovin_gem@mail.ru ).

Журнал «Современная наука: актуальные проблемы теории и практики»

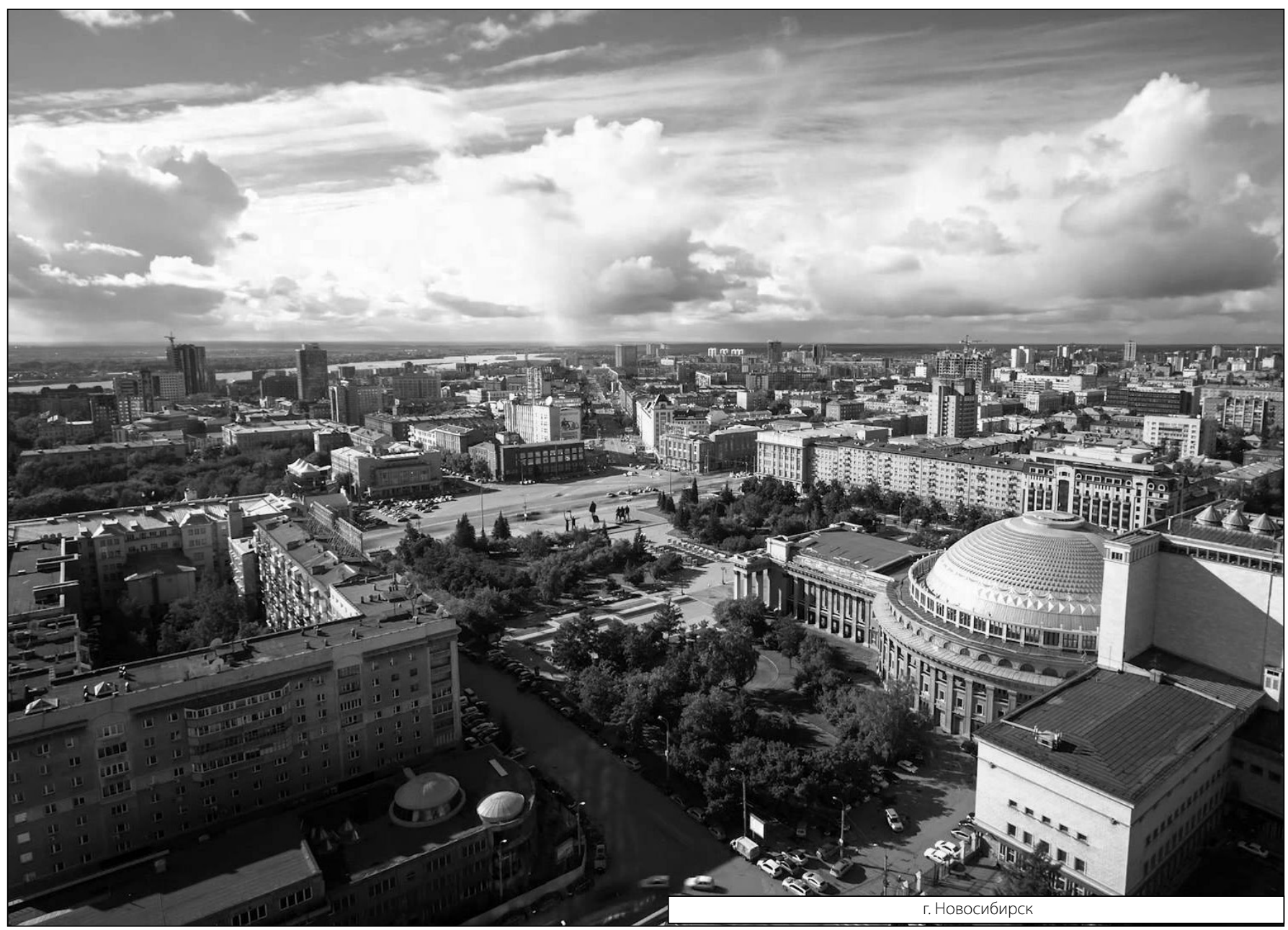

